Research Article

\title{
Facile Synthesis of Hollow Carbon Nanospheres by Using Microwave Radiation
}

\author{
Jiareng Chen $(\mathbb{D}$, Jiaqi Lin $(\mathbb{D}$, Bin Cui $(\mathbb{D}$, and Yang Liu $\mathbb{D}$ \\ Department of Biomedical Engineering, Sun Yat-sen University, Guangzhou, China 510006 \\ Correspondence should be addressed to Yang Liu; liuyang56@mail.sysu.edu.cn
}

Received 16 December 2019; Revised 8 February 2020; Accepted 13 February 2020; Published 11 March 2020

Academic Editor: Huining Xiao

Copyright ( 2020 Jiareng Chen et al. This is an open access article distributed under the Creative Commons Attribution License, which permits unrestricted use, distribution, and reproduction in any medium, provided the original work is properly cited.

\begin{abstract}
Carbon-based nanomaterials have attracted much research interest in recent years due to their excellent chemical and physiological properties such as chemical stability, low cytotoxicity, and biocompatibility. The traditional methods to prepare hollow carbon nanospheres require complicated instrumentation and harsh chemicals, including high-temperature furnace, gas inlets, and hydrogen fluoride etching. Herein, we propose a new strategy to prepare hollow carbon nanospheres in a simple and fast manner by using microwave radiation. Polypyrrole-coated silica core-shell nanoparticles $\left(\mathrm{SiO}_{2} @ \mathrm{PPy} \mathrm{NPs}\right)$ were firstly prepared and subsequently processed by microwave radiation and aqueous alkaline solution to obtain the hollow carbon nanospheres. This facile method has potent potential to be utilized in the preparation of different types of hollow carbon nanospheres with various microstructure and elemental composition.
\end{abstract}

\section{Introduction}

Carbon nanomaterials, such as carbon nanospheres, mesoporous carbon nanomaterials, and carbon dots, are considered to be important for the next-generation structural, energy, and bioengineering materials due to their unique physical, chemical, optical, mechanical, and thermal properties, together with their high stability, good conductivity, and high biocompatibility. Carbon nanospheres have been widely explored and applied in different research fields $[1,2]$, such as electrode materials [3], flexible electronic devices [4], bioimaging [5], and drug carriers [6]. For example, sodium-ion hybrid supercapacitors which used mesoporous $\mathrm{Nb}_{2} \mathrm{O}_{5} @$ Carbon core-shell nanoparticles and reduced graphene oxide as the anode material showed high energy/power densities and long cycle life [7]. Carbon dots, synthesized from the folic acid, exhibited selectivity towards cancer cells with folate receptors, making such cells easily distinguishable in fluorescence microscopy imaging [8]. A DOX-loaded HB5modified mesoporous carbon nanomaterial-based drug delivery system provides highly efficient methods for the treatment of HER2-positive cancers, which has better therapeutic efficacy and lower side effects [9]. Among variant mor- phology of carbon, hollow carbon nanospheres have received more and more attention due to their unique properties such as encapsulation ability, controllable permeability, surface functionality, high surface-to-volume ratios, and excellent chemical and thermal stability [10]. The application prospects of hollow carbon nanospheres are broad. The traditional preparation methods of hollow carbon nanospheres include emulsion synthesis [11], soft-templating synthesis [12], hard-templating synthesis [13], modified Stöber method [14], and template-free strategy [15]. These methods often need to be carried out under high temperatures and pressures, while the process is complicated, and the processing time is considerably elongated [16]. Furthermore, it was hard to control the morphology of the target product during the soft-templating synthesis, and the template removal process was often challenging during the hard-templating synthesis [10].

Herein, we intend to use a microwave rapid nanosynthesis method to synthesize hollow carbon nanospheres. As a nontoxic and biocompatible conductive polymer material, PPy has been used in electrode materials [17], in vivo photodynamic and photothermal therapy [18], etc. We have explored a rapid synthesis method of hollow carbon 
TABLE 1: Microwave parameters of each group.

\begin{tabular}{lcccc}
\hline Samples & Carbon fiber mass (mg) & $\mathrm{SiO}_{2} @ P P y$ NPs : carbon fiber (mass ratio) & Microwave time (min) & Subsequent treatment \\
\hline MW1 & 1 & $100: 1$ & 5 & $\mathrm{H}_{2} \mathrm{O}$ washing \\
MW2 & 3 & $100: 3$ & 5 & $\mathrm{H}_{2} \mathrm{O}$ washing \\
MW3 & 5 & $100: 5$ & 2 & $\mathrm{H}_{2} \mathrm{O}$ washing \\
Hollow C & 1 & $100: 1$ & 5 & $\mathrm{NaOH}$ stirring \\
\hline
\end{tabular}

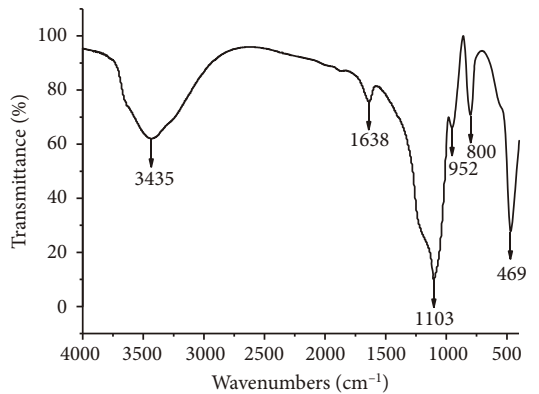

(a)

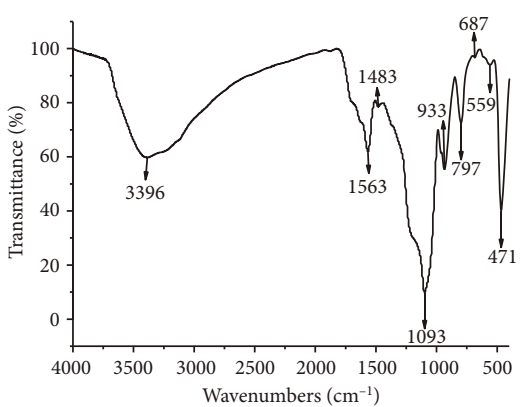

(b)

Figure 1: FT-IR spectra of (a) $\mathrm{SiO}_{2}$ NPs and (b) $\mathrm{SiO}_{2} @ P P y$ NPs.

nanospheres by using PPy as the carbon source under microwave irradiation. This method is environmentally friendly and eliminates the need of harsh conditions. It takes only a domestic microwave oven to synthesize the carbon nanospheres in a short time (1-30 min). Then, hollow carbon nanospheres are obtained by using $\mathrm{NaOH}$ to etch the template. By controlling the process parameters and precursor materials used in the microwave process, carbon nanospheres with different structure and morphology can be obtained.

\section{Experimental Section}

2.1. Materials. Tetraethyl orthosilicate (99.99\%) was purchased from Aladdin. Ammonia solution (25\%) and ethanol absolute (99.7\%) were purchased from Tianjin Zhiyuan Reagent Co., Ltd. Pyrrole was purchased from Macklin. Chondroitin sulfate A sodium salt from bovine trachea was purchased from Sigma. Ammonium persulfate was purchased from Sinopharm Chemical Reagent Co., Ltd. Sodium hydroxide was purchased from Tianjin Damao.

2.2. Synthesis of $\mathrm{SiO}_{2} @ P P y$ NPs. $\mathrm{SiO}_{2} \mathrm{NPs}$ were synthesized according to the classical method reported by Stöber et al. [19]. Briefly, add $5 \mathrm{~mL}$ ammonia water and $1 \mathrm{~mL}$ pure water to $50 \mathrm{~mL}$ ethanol with stirring. Add $5 \mathrm{~mL}$ tetraethyl orthosilicate (TEOS), and continue to stir for $2 \mathrm{~h}$. After centrifugation (4000 rpm, $15 \mathrm{~min}$ ), the products were washed by water twice and ethanol for one time, then dried to obtain silicon nanospheres. PPy coating was according to method described by Zhou et al. [20]. $0.2 \mathrm{~g} \mathrm{SiO}_{2} \mathrm{NPs}$ templates were dispersed to $100 \mathrm{~mL}$ water by ultrasonic, and then $0.1 \mathrm{~g}$ Chondroitin sulfate A sodium salt was added to form a solution with a concentration of $0.001 \mathrm{~g} / \mathrm{mL}$. The solution was stirred overnight, so that the $\mathrm{SiO}_{2} \mathrm{NPs}$ could fully absorb chondroitin sulfate. $0.070 \mathrm{~mL}$ pyrrole monomer was added to the mixture. Then $\left(\mathrm{NH}_{4}\right)_{2} \mathrm{~S}_{2} \mathrm{O}_{8}\left(0.228 \mathrm{~g}, 10 \mathrm{~mL} \mathrm{H} \mathrm{H}_{2} \mathrm{O}\right)$ was added to the system, and the mixture was stirred at $4^{\circ} \mathrm{C}$ for $12 \mathrm{~h}$. The samples were washed twice by water and once by alcohol (5500 rpm, $20 \mathrm{~min}$ ), then dried for $12 \mathrm{~h}$ at $60^{\circ} \mathrm{C}$.

2.3. Microwave SiO $\mathrm{O}_{2} @ P P y$ NPs and Template Etching. After mixing 100 mg SiO $\mathrm{S}_{2} @ P$ Py NPs with carbon fiber at different mass ratios, microwave reactions were initiated at $1000 \mathrm{~W}$ in different reaction time. The conditions for each group are recorded in Table 1 and named as MW1, MW2, and MW3. Then the microwave products were washed and centrifuged ( $5500 \mathrm{rpm}, 15 \mathrm{~min}$ ) to obtain the carbonization products with silicon spheres templates. Silicon cores were then removed by stirring in $1 \mathrm{M} \mathrm{NaOH}$, and the Hollow $\mathrm{C}$ was obtained.

\section{Results and Discussion}

According to the method reported by Zhou et al. [20], we synthesized $\mathrm{SiO}_{2} @ P P y$ NPs as templates for carbonization. In this method, the $\mathrm{SiO}_{2}$ NPs surfaces are modified by chondroitin sulfate A sodium (CSA) so that the PPy can be doped by the CSA molecules in situ. Besides, the CSA molecules are negatively charged so they can repel each other and make the PPy layer uniformly distributed. In order to inspect the functional groups on the surface of the samples, we use Fourier transform infrared spectroscopy (FT-IR) to characterize the as-synthesized $\mathrm{SiO}_{2} @ P P y$ NPs (Figure 1). In Figures 1(a) and 1 (b), the absorption peaks near $3400 \mathrm{~cm}^{-1}$ are attributed to $\mathrm{H}-\mathrm{O}-\mathrm{H}$ stretching [21]. In Figure $1(\mathrm{a})$, the strong peaks at 1103,800 , and $469 \mathrm{~cm}^{-1}$ corresponded to the antisymmetric vibration peaks of $\mathrm{Si}-\mathrm{O}-\mathrm{Si}$ and the symmetric and curved vibration peaks of Si-O bonds. The peak at $952 \mathrm{~cm}^{-1}$ belongs to the bending vibration absorption of Si-OH. In Figure 1(b), the absorption at $1563 \mathrm{~cm}^{-1}$ is assigned to C-C stretching or $\mathrm{C}-\mathrm{N}$ stretching [22]. The band at $1483 \mathrm{~cm}^{-1}$ corresponds to $\mathrm{C}-\mathrm{N}$ stretching, and it may also contribute by the 


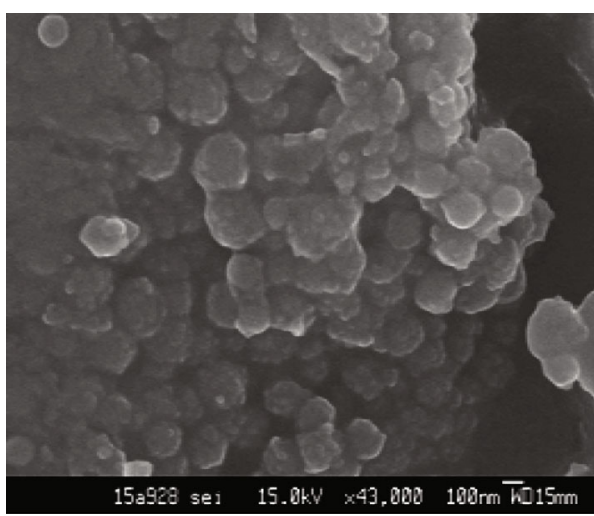

(a)

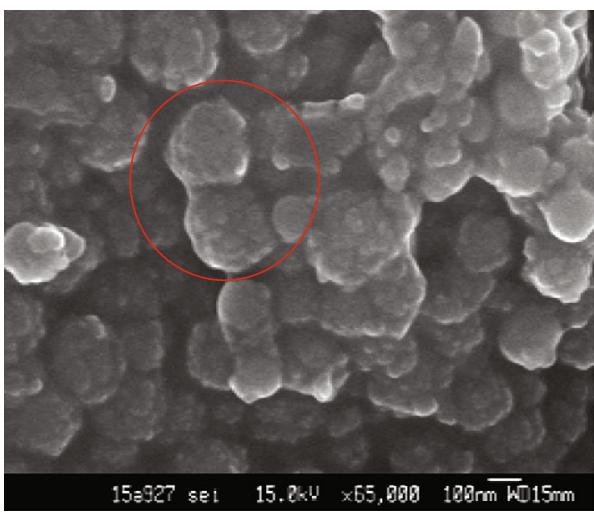

(c)

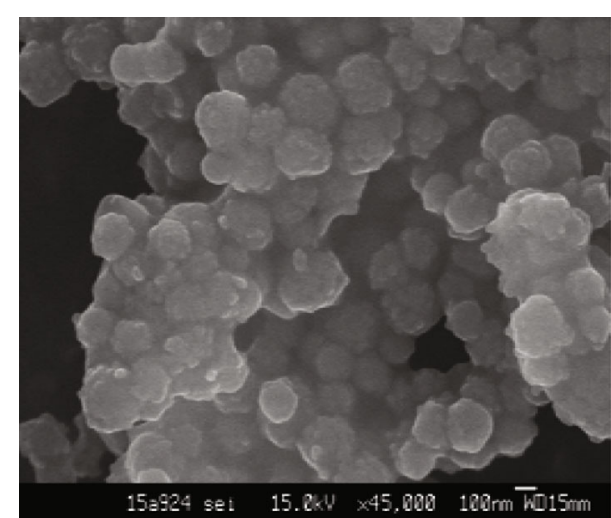

(b)

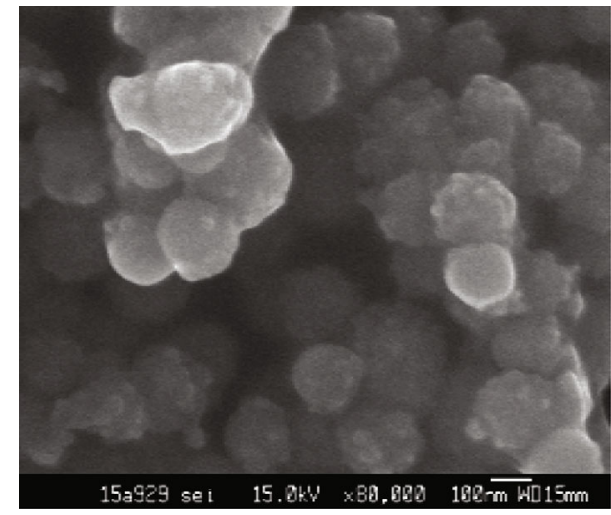

(d)

Figure 2: SEM images of (a-d) $\mathrm{SiO}_{2} @ P P y$ NPs in different magnifications. (c) is the close up view of (a) and shows the separation state of $\mathrm{SiO}_{2} @ \mathrm{PPy} \mathrm{NPs}$.

dissymmetrical and symmetric ring-stretching modes [23]. The peaks near $1220 \mathrm{~cm}^{-1}$ and $933 \mathrm{~cm}^{-1}$ suggest the doped state of PPy [23]. By comparing Figures 1(a) and 1(b), we speculated that the PPy shells of $\mathrm{SiO}_{2} @ P P y$ NPs are thin because of the strong Si-O-Si stretching absorption peak near $1100 \mathrm{~cm}^{-1}$. The characteristic absorption peaks of PPy on the $\mathrm{SiO}_{2} @$ PPy NPs surfaces indicate that PPy is successfully coated on the surfaces of $\mathrm{SiO}_{2}$ NPs.

We then use scanning electron microscope (SEM) to analyze the shape and size of the as-prepared $\mathrm{SiO}_{2} @ P P y$ NPs. In Figure 2, we can see that compared to the $\mathrm{SiO}_{2} \mathrm{NPs}$ (Figure S1), the surface of $\mathrm{SiO}_{2} @ \mathrm{PPy} \mathrm{NPs}$ is considerably rougher. The PPy was found to precipitate on the surface of the $\mathrm{SiO}_{2} \mathrm{NPs}$, forming particulate microstructure. Due to the cross-linking of the PPy coating, the as-obtained $\mathrm{SiO}_{2} @ \mathrm{PPy} \quad \mathrm{NPs}$ generally exhibited an aggregated morphology under SEM, but the structure of individual $\mathrm{SiO}_{2} @ \mathrm{PPy} \mathrm{NPs}$ can be still clearly identified (Figure 2(c)). In the SEM images, the particle sizes of the $\mathrm{SiO}_{2} @ P P y$ NPs are measured to be ranged from $200 \mathrm{~nm}$ to $300 \mathrm{~nm}$. The existence of PPy coating on the surface of the $\mathrm{SiO}_{2} @ P P y$ NPs was further verified by transmission electron microscopy (TEM). In Figure 3, it can be observed that the $\mathrm{SiO}_{2} @$ PPy NPs have a core-shell structure. From the redcircle-marked part of Figure 3(d), the phase boundary between PPy and silica can be seen clearly. The $\mathrm{SiO}_{2} \mathrm{NP}$ can be observed as the solid core, while PPy forms an intact and continuous thin nanoshell on the silica surface. The average thickness of the PPy nanoshells was measured to be $19.62 \pm 1.78 \mathrm{~nm}$ based on the TEM images. A series of experiments were also conducted to explore the appropriate diameter of silicon spheres (Figure S1, Table S1). Next, we investigated the effect of CSA concentration on the thickness of PPy shell (Figure S2 and S3). In Figure S2, it is obvious that the surface of the spheres in the CSA-doped group (Figure S2b-f) is rougher than that in the control group (Figure S2a) without CSA doping. It indicates that CSA can modify the surface of $\mathrm{SiO}_{2}$ NPs and promote the coating of PPy. TEM was then used to compare the difference of PPy coating obtained from five different CSA concentrations (Figure S3). Among them, the PPy layer of the $0.1 \mathrm{wt} \%$ group (Figure S3a) is the most uniform and continuous. With increasing the concentration of CSA, the agglomeration of $\mathrm{SiO}_{2} @ \mathrm{PPy} \mathrm{NPs}$ becomes weaker, and the granular shape of $\mathrm{PPy}$ on $\mathrm{SiO}_{2} \mathrm{NPs}$ surface becomes more obvious. And in the $0.4 \mathrm{wt} \%$ and $0.5 \mathrm{wt} \%$ groups, where the CSA concentrations are over $0.3 \mathrm{wt} \%$ (Figure S3d and S3e), it shows obvious discontinuity of PPy shells. The weaker agglomeration of $\mathrm{SiO}_{2} @ \mathrm{PPy} \mathrm{NPs}$ is the effect of CSA for it can play a role in constructing the grid structure in the reaction and effectively disperse the $\mathrm{SiO}_{2} \quad \mathrm{NPs}$ via electrostatic interactions [20]. The CSA chains with lots of 


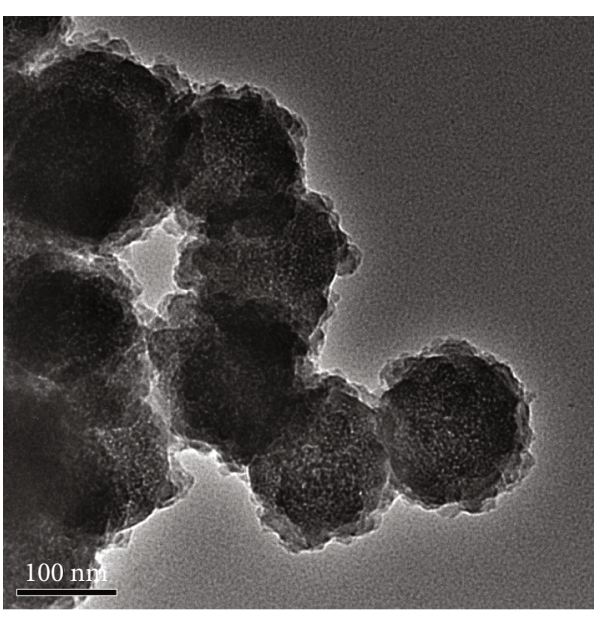

(a)

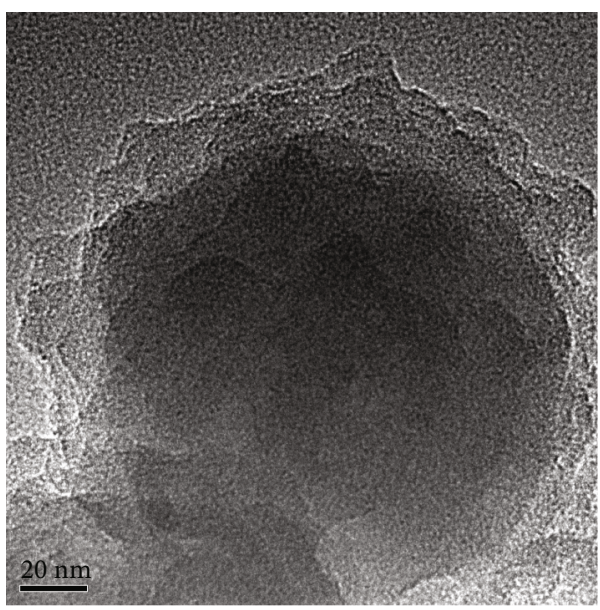

(c)

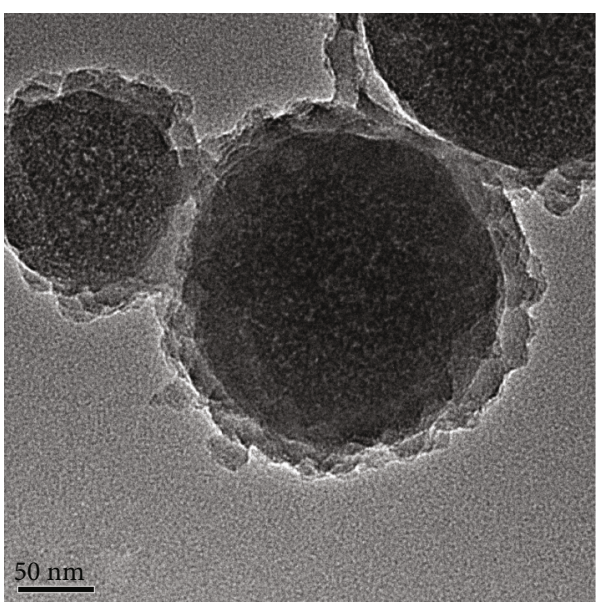

(b)

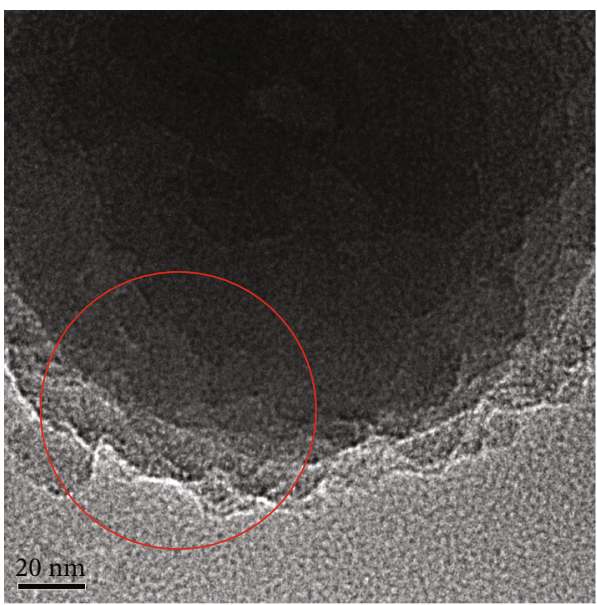

(d)

Figure 3: TEM images of (a-d) $\mathrm{SiO}_{2} @ P P y$ NPs in different magnifications. (d) is the close view of (b). (d) The circled part shows the doublelayer structure clearly.

sulphonic $\left(-\mathrm{SO}_{3}^{-}\right)$and carboxylic $\left(-\mathrm{COO}^{-}\right)$groups can interact with $\mathrm{Py}^{+}$and form intermediate complexes [24]. When the oxidative polymerization was triggered, the PPy was preferentially formed along the CSA chains [24]. In higher CSA concentrations $(\geq 0.3 \mathrm{wt} \%)$, more CSA molecules would adsorb on the surface of the $\mathrm{SiO}_{2} \mathrm{NPs}$, resulting in higher steric hindrance that hinders the formation of a continuous PPy coating layer. To explore the relationship between size and CSA concentration, we randomly counted more than 50 SiO $2 @ P P y$ NPs for each of the different CSA concentrations. The size (in SEM figures) and thickness (in TEM figures) distributions are shown in Figure S4. In the 0.2 wt $\%$ group, the $\mathrm{SiO}_{2} @ \mathrm{PPy}$ NPs feature the largest average size $(245.08 \pm 6.11 \mathrm{~nm})$ and the thickest PPy layer $(23.60 \pm 2.20 \mathrm{~nm})$. When the concentration is higher than $0.2 \mathrm{wt} \%$, with increasing the concentration of CSA, the size of $\mathrm{SiO}_{2} @ P P y$ NPs becomes smaller, and the PPy layers become thinner.

The $\mathrm{SiO}_{2} @ P P y$ NPs were then microwave-treated under different conditions in Table 1, which were labeled as microwave-treated products 1-3 (MW1, MW2, and MW3), and samples obtained after a $1 \mathrm{~mol} / \mathrm{L} \mathrm{NaOH}$ stirring treat- ment were named as hollow carbon nanospheres (Hollow C). The morphology and microstructure of the products after microwave radiation were characterized by TEM. In Figures 4(a)-4(c), we can clearly see the shells' morphology changed after microwave, and the $\mathrm{SiO}_{2} @ \mathrm{C}$ NPs still maintain the core-shell structure. The average thickness of shells of $\mathrm{SiO}_{2} @ \mathrm{C} \mathrm{NPs}$ is $29.5 \pm 5.5 \mathrm{~nm}$. Compared to the $\mathrm{SiO}_{2} @ P P y$ NPs, the shells of the products after microwave radiation become thicker, and the larger standard deviation indicates the heterogeneity of shells. These changes indicate that carbonation reactions may have taken place in the products during microwave. After stirring in $\mathrm{NaOH}$ solution, we can obtain carbon nanospheres with hollow core formed by removing $\mathrm{SiO}_{2}$ NPs templates, and the average hollow size is $135.7 \mathrm{~nm}$ (Figures 4(d)-4(f)). The edges of the hollow cores in Hollow $\mathrm{C}$ are smooth; however, the shells are heterogeneity, and most of them are incomplete. Also, there is no porous structure that can be observed in Hollow C.

Elemental analysis (EA) was conducted on $\mathrm{SiO}_{2} @ \mathrm{PPy}$ NPs and $\mathrm{SiO}_{2} @ \mathrm{C}$. In Table 2, it can be seen that the weight percentage of carbon elements of $\mathrm{SiO}_{2} @ \mathrm{PPy}$ is around 15\% and is similar to the products after microwave. In the 


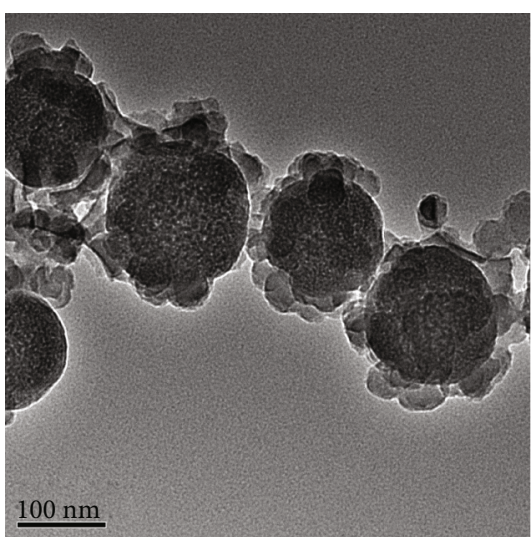

(a)

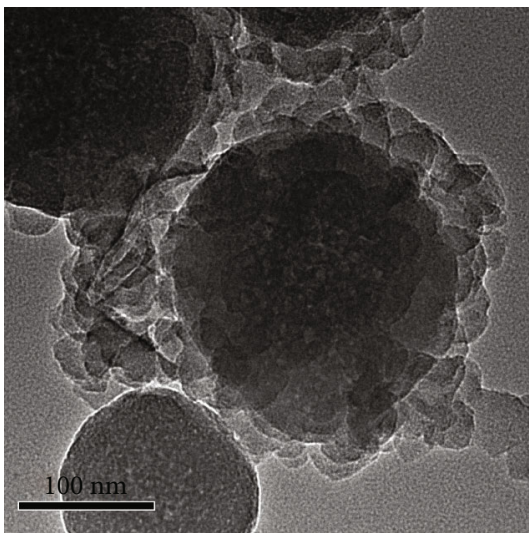

(c)

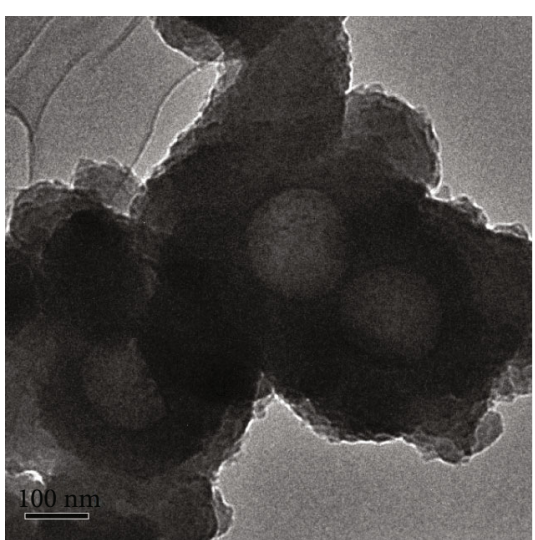

(e)

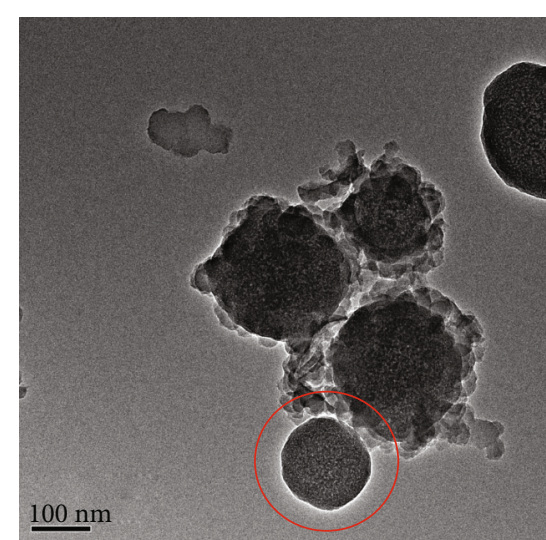

(b)

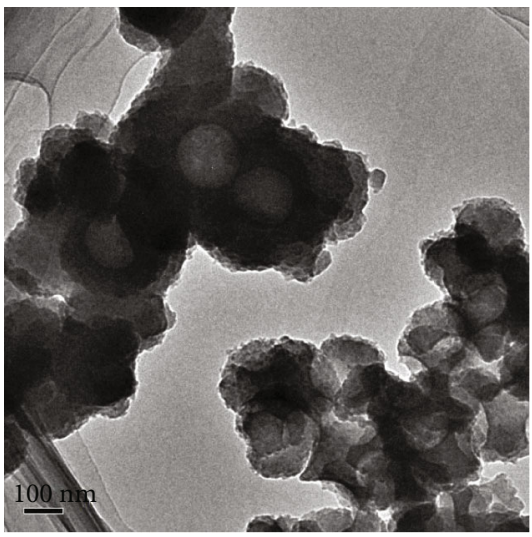

(d)

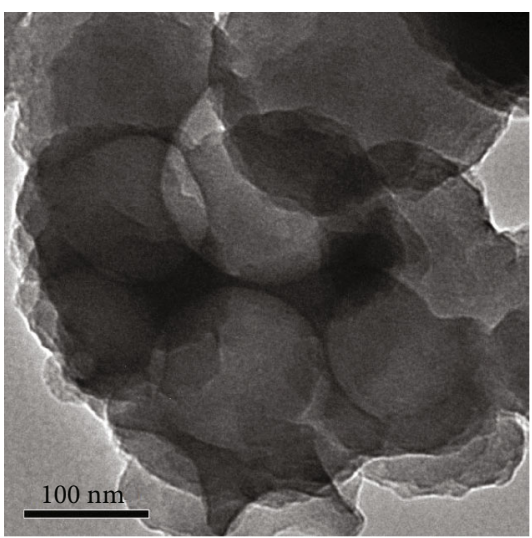

(f)

Figure 4: TEM images of $\mathrm{SiO}_{2} @ \mathrm{C} N P s(\mathrm{a}-\mathrm{c})$ and Hollow $\mathrm{C}(\mathrm{d}-\mathrm{f}) .(\mathrm{b})$ The circled part shows one of the cores lose its shell during the reaction.

TABLE 2: EA results of $\mathrm{SiO}_{2} @ P P y$, samples after microwave, and Hollow C.

\begin{tabular}{lccccc}
\hline Samples & $\mathrm{C} \%$ & $\mathrm{H} \%$ & $\mathrm{~N} \%$ & $\mathrm{C} / \mathrm{H}$ & $\mathrm{C} / \mathrm{N}$ \\
\hline $\mathrm{SiO}_{2} @ \mathrm{PPy}$ & 15.65 & 2.51 & 3.99 & 6.2313 & 3.9223 \\
$\mathrm{MW} 1$ & 15.86 & 2.22 & 4.33 & 7.1487 & 3.6588 \\
$\mathrm{MW} 2$ & 15.45 & 1.97 & 4.28 & 7.8247 & 3.6111 \\
$\mathrm{MW} 3$ & 15.55 & 2.1 & 4.15 & 7.3967 & 3.7439 \\
Hollow C & 38.06 & 2.79 & 10.48 & 13.654 & 3.6302 \\
\hline
\end{tabular}

meantime, the $\mathrm{C} / \mathrm{H}$ ratio increases from 6.2313 to over 7 after microwave radiation, which indicates that $\mathrm{SiO}_{2} @ \mathrm{PPy}$ is carbonized. Hollow $\mathrm{C}$ is the product of $\mathrm{MW} 1$ after $\mathrm{NaOH}$ treatment, and the contents of carbon, nitrogen, and $\mathrm{C} / \mathrm{H}$ ratio are $38.06 \%, 10.48 \%$, and 13.654. Compared to MW1, these parameters significantly increased, which suggests that the effect of microwave carbonization is good and the $\mathrm{SiO}_{2} \mathrm{NPs}$ were successfully etched. Carbon cannot be dissolved by the aqueous alkaline solution so it remains after $\mathrm{NaOH}$ stirring resulting in the increase of weight percentage of carbon elements and $\mathrm{C} / \mathrm{H}$ ratio. This demonstrates that the 
carbonization reaction happened. As can be seen from Table 2, the sum of the percentage of $\mathrm{C}, \mathrm{H}$, and $\mathrm{N}$ elements is only slightly higher than $20 \%$ in $\mathrm{SiO}_{2} @ \mathrm{C}$ while in Hollow $\mathrm{C}$ it is slightly more than $50 \%$. It shows that there are other elements in the samples with a high content cannot be detected, considering to be $\mathrm{Si}$ and $\mathrm{O}$ elements.

In the process of microwave radiation, it is the PPy in the shell to be carbonized, so we are more concerned about the change of element content in the surface. Xray photoelectron spectroscopy (XPS) was used to study the surface element content. Figure 5 shows that the samples contain elements such as $\mathrm{Na}, \mathrm{S}, \mathrm{Si}, \mathrm{O}, \mathrm{N}$, and $\mathrm{C}$, and the atomic percentages of various elements can be obtained by integrating the peak area (Table 3). The $\mathrm{Na}$ and $\mathrm{S}$ elements come from the CSA added, and Si comes from silicon sphere core. Meanwhile, peaks at around $533 \mathrm{eV}$ are attributed to $\mathrm{O} 1 \mathrm{~s}$, which can be derived from CSA and $\mathrm{SiO}_{2}$ NPs detected through the shell in $\mathrm{SiO}_{2} @ P P y$ NPs and $\mathrm{SiO}_{2} @ \mathrm{C}$ NPs. Peaks at $400 \mathrm{eV}$ and $285 \mathrm{eV}$ are $\mathrm{N} 1 \mathrm{~s}$ and $\mathrm{C} 1 \mathrm{~s}$ peaks. Nitrogen mainly comes from the PPy heterocyclic ring, and carbon comes from the carbon skeleton of the products.

According to the results, the atomic percentage of $\mathrm{C}$ elements is the highest (75.4\%), followed by $\mathrm{O}, \mathrm{Si}$, and $\mathrm{N}$ in $\mathrm{SiO}_{2} @ \mathrm{PPy} \mathrm{NPs}$. In MW1 and MW2, the C content decreases to $57.76 \%$ and $55.44 \%$, respectively, after the microwave treatment, while the C content in MW3 is significantly higher (70.09\%) than MW1 and MW2. However, there are only slight differences among the C contents of the MW1, MW2, and MW3 samples according to the EA analysis. It thus indicates that during the sample preparation process of MW3, a higher mass ratio of the carbon fiber and a shorter microwave time may result in a higher $\mathrm{C}$ content on the sample surface. The EA analysis of the $\mathrm{O}$ element indicates that the atomic percentage of $\mathrm{O}$ in MW3 increases slightly to $19.83 \%$ and in MW1 and MW2 increases up to $27.34 \%$ and $28.42 \%$, respectively. Compared with the EA result that the weight percentage of $\mathrm{C}$ has no obvious change in $\mathrm{SiO}_{2} @ P P y$ NPs and $\mathrm{SiO}_{2} @ \mathrm{C}$, this shows that the $\mathrm{C}$ elements do not lose a lot in the reaction and it is the addition of $\mathrm{O}$ elements in the shells that mainly causes the decrease of the proportion of $\mathrm{C}$ elements in $\mathrm{SiO}_{2} @ \mathrm{C}$. Also, these changes indicate that the effect of microwave time on the element ratio of $\mathrm{C}$ and $\mathrm{O}$ is greater than the mass ratio of carbon fiber in the precursor. By increasing the radiation time, the carbon content decreases while the oxygen content increases. As for the percentage of $\mathrm{Si}$ elements, it is 2.9\% in $\mathrm{SiO}_{2} @ \mathrm{PPy} \mathrm{NPs}$ and increases to $8.82 \%, 9.88 \%$, and $3.62 \%$ in MW1, MW2, and MW3 individually. The possible cause of this is that a portion of the $\mathrm{SiO}_{2}$ cores lost their shells in the reaction, which can be seen in Figure 4(b) (red circle), and the reaction between $\mathrm{SiO}_{2}$ and $\mathrm{C}$ is also expected to attribute to this. $\mathrm{SiO}_{2}$ can be reduced by carbon under the high temperature, and the happening of this reaction can also let a few Si elements mix into the shells.

Compared with MW1 washed by water, the proportion of carbon atoms in the products treated by $\mathrm{NaOH}$ increases to $78.85 \%$, while the proportion of silicon elements decreases to $1.16 \%$, and the weight percentages of $\mathrm{C}$ and $\mathrm{N}$ elements

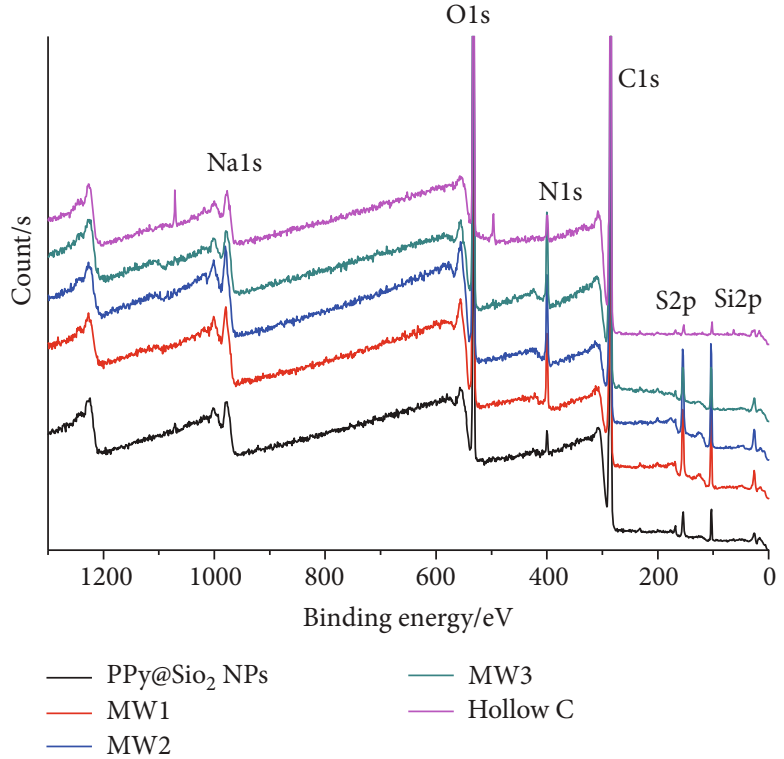

FIgURE 5: XPS results of $\mathrm{SiO}_{2} @ P P y$ NPs, samples after microwave, and Hollow C.

TABLE 3: The atomic percentages and peak positions of different elements obtained by XPS characterization of $\mathrm{SiO}_{2} @ P P y$ NPs, samples after microwave, and Hollow C.

\begin{tabular}{lccccc}
\hline Elements & $\mathrm{SiO}_{2} @ P P y ~ N P s$ & $\mathrm{MW1}$ & $\mathrm{MW} 2$ & MW3 & Hollow C \\
\hline C peak $(\mathrm{eV})$ & 284.8 & 284.81 & 284.82 & 284.81 & 284.79 \\
$\mathrm{C}(\%)$ & 75.4 & 57.76 & 55.44 & 70.09 & 78.85 \\
O peak $(\mathrm{eV})$ & 532.63 & 533.03 & 532.99 & 532.81 & 532.2 \\
$\mathrm{O}(\%)$ & 19.57 & 27.34 & 28.42 & 19.83 & 17.14 \\
$\mathrm{~N}$ peak $(\mathrm{eV})$ & 399.78 & 399.77 & 399.81 & 399.83 & 399.72 \\
$\mathrm{~N}(\%)$ & 1.53 & 6.09 & 6.26 & 6.15 & 2.02 \\
Si peak $(\mathrm{eV})$ & 103.45 & 103.81 & 103.76 & 103.78 & 102.1 \\
Si $(\%)$ & 2.9 & 8.82 & 9.88 & 3.62 & 1.16 \\
\hline
\end{tabular}

both increase in the EA results. It shows that the silicon cores were successfully etched, and Hollow $\mathrm{C}$ was obtained. However, the percentage of silicon atoms on the surface decreases by only $7.66 \%$, while the percentage of carbon atoms increases by $21.09 \%$. This suggests that the percentage of carbon atoms rise is not totally formed by removing the silicon cores, and there are some other reasons: (1) The oxygen content decreases in Hollow $\mathrm{C}$, which may be caused by the break of the noncovalently bound between CSA and the particles. (2) The nitrogen in the system mainly exists in the heterocyclic ring of PPy, which content also decreases after $\mathrm{NaOH}$ treatment. This indicates that the residual PPy in the shells was also removed. However, the increase of weight percentage of $\mathrm{N}$ in the EA results is because of the etching of silicon cores.

The deconvolution of the XPS peaks was performed by using the software of XPSpeak41 (Figure 6). It can be seen that the proportion of $\mathrm{C}-\mathrm{C}$ is the largest in $\mathrm{C} 1 \mathrm{~s}$ and the remaining components of $\mathrm{C}=\mathrm{C}, \mathrm{C}=\mathrm{O}$, and $\mathrm{C}-\mathrm{O}$ are basically 

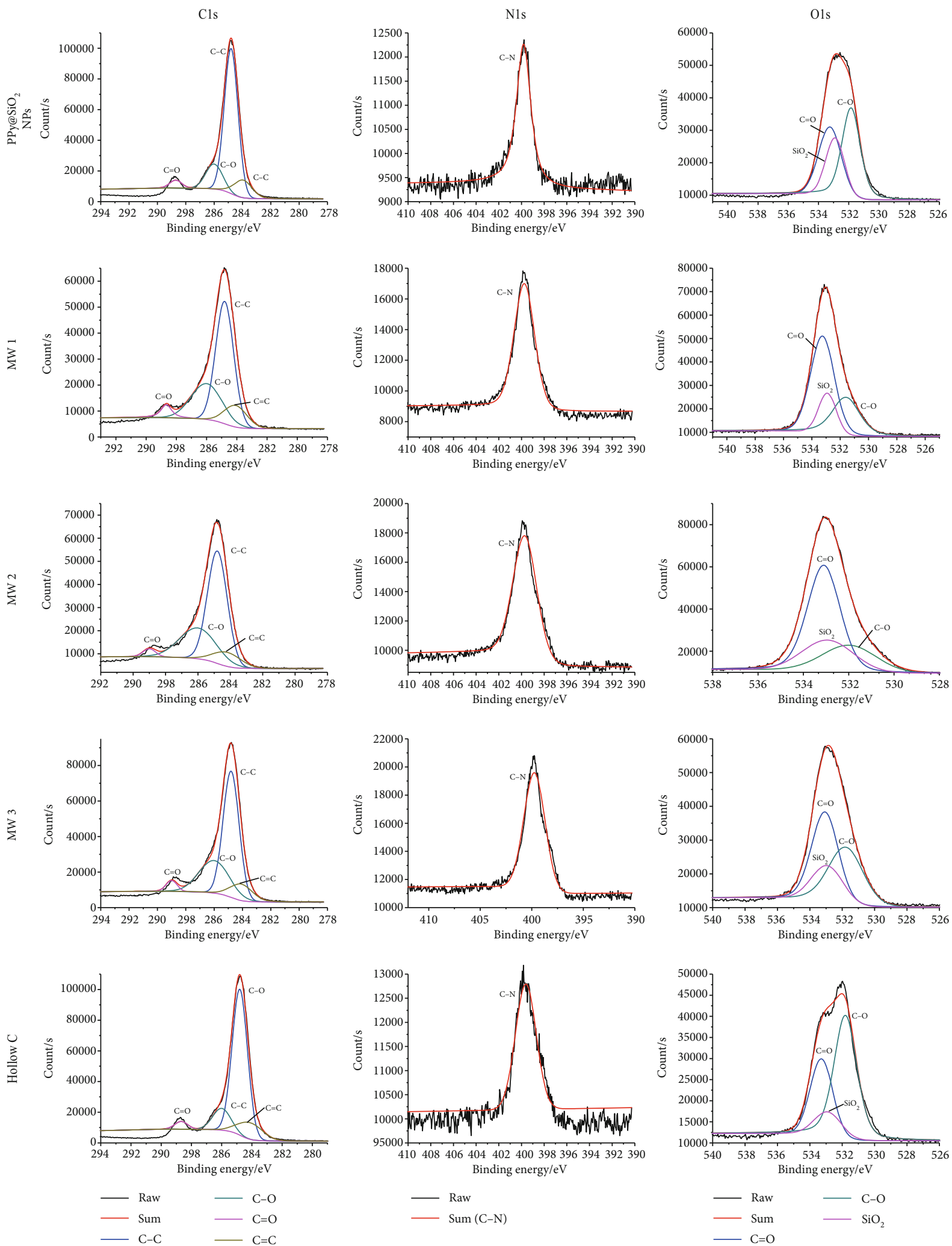

Figure 6: XPS spectra of each group in C1s, N1s, and O1s.

close. According to the peak separation of $\mathrm{O} 1 \mathrm{~s}$, the ratio of $\mathrm{C}$ $\mathrm{O}$ is higher than that of $\mathrm{C}=\mathrm{O}$ in $\mathrm{SiO}_{2} @ P P y$ NPs, and while the results change in the samples after microwave, the ratio of $\mathrm{C}=\mathrm{O}$ exceeds that of $\mathrm{C}-\mathrm{O}$. The proportion of $\mathrm{C}-\mathrm{O}$ in $\mathrm{Hol}-$ low $\mathrm{C}$ is higher than that of $\mathrm{C}=\mathrm{O}$, which may be due to the aldol reaction or disproportionation. A part of $\mathrm{C}=\mathrm{O}$ is reduced to $\mathrm{C}-\mathrm{O}$, so the proportion of $\mathrm{C}-\mathrm{O}$ rises while the proportion of $\mathrm{C}=\mathrm{O}$ decreases. 


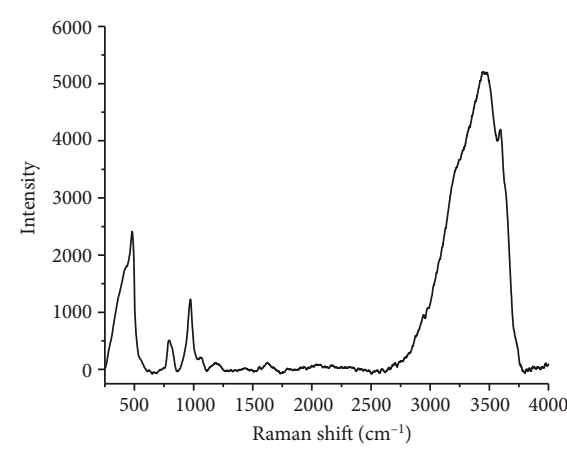

(a)

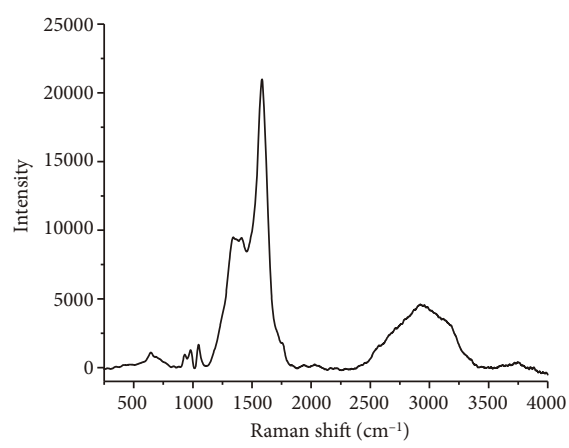

(c)

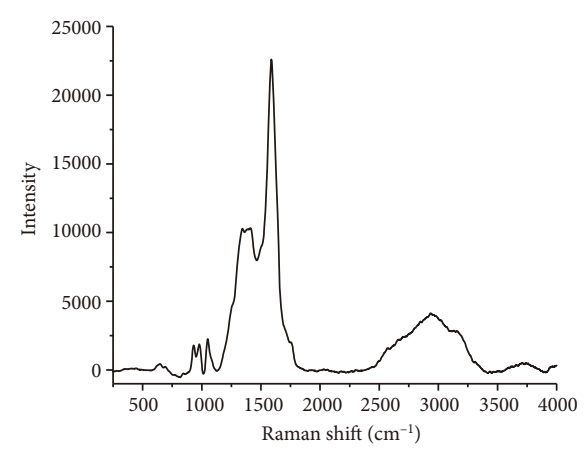

(b)

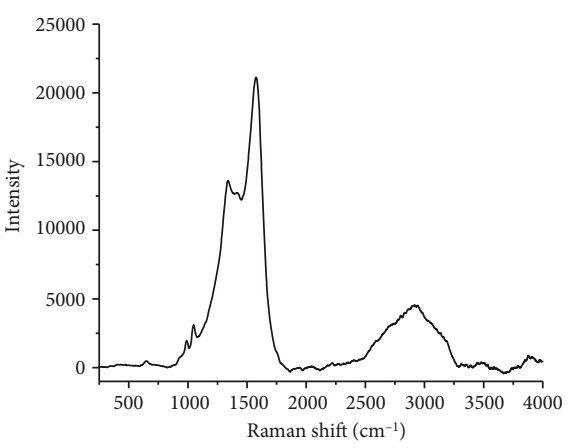

(d)

Figure 7: Raman results of (a) $\mathrm{SiO}_{2}$ NPs, (b) $\mathrm{SiO}_{2} @ P P y$ NPs, (c) $\mathrm{SiO}_{2} @ \mathrm{C}$ NPs, and (d) Hollow C.

Raman analyses were performed to deeper study the form of carbon in $\mathrm{SiO}_{2} \mathrm{NPs}, \mathrm{SiO}_{2} @ \mathrm{PPy} \mathrm{NPs}, \mathrm{SiO}_{2} @ \mathrm{C} \mathrm{NPs}$, and Hollow C (Figure 7). In the spectrum of the $\mathrm{SiO}_{2} \mathrm{NPs}$ (Figure 7(a)), we can see a small peak at $460 \mathrm{~cm}^{-1}$ and a wide peak at $3454 \mathrm{~cm}^{-1}$. These two peaks disappeared after PPy layers were coated (Figure $7(b)$ ) and new peaks near $1360 \mathrm{~cm}^{-1}$ (D peak), $1580 \mathrm{~cm}^{-1}$ (G peak), and $2930 \mathrm{~cm}^{-1}$ (G $+\mathrm{D}$ peak) relating to carbon materials appeared $[25,26]$, which can also be observed in $\mathrm{SiO}_{2} @ \mathrm{C}$ NPs (Figure 7(c)) and Hollow C (Figure 7(d)). D-band represents structural defects of carbon, and G-band comes from in-plane vibration of $\mathrm{sp}^{2}$-bonded crystalline carbon, so the $I_{\mathrm{D}} / I_{\mathrm{G}}$ intensity ratio can give the information about the graphitization degree [26]. $I_{\mathrm{D}} / I_{\mathrm{G}}$ is $0.46,0.44$, and 0.64 in $\mathrm{SiO}_{2} @ P P y \mathrm{NPs}, \mathrm{SiO}_{2} @ \mathrm{C}$ NPs, and Hollow C, respectively. Compared to $\mathrm{SiO}_{2} @ \mathrm{PPy}$ NPs, $I_{\mathrm{D}} / I_{\mathrm{G}}$ in $\mathrm{SiO}_{2} @ \mathrm{C} \mathrm{NPs}$ is a little higher corresponding to the decrease of the proportion of C-C in XPS results. The increasing $I_{\mathrm{D}} / I_{\mathrm{G}}$ ratio in Hollow $\mathrm{C}$ indicates the defects and the degree of nongraphitized carbon increased, which may be due to the change of oxygen-containing functional groups [27] and the reduction of $\mathrm{sp}^{2}$ domains during the $\mathrm{NaOH}$ stirring.

Microwave heating method is expected to have the characteristics of faster heating rate and higher efficiency than the traditional heating method. By absorbing microwave energy, it heats the $\mathrm{SiO}_{2} @ \mathrm{PPy} \mathrm{NPs}$ and turns them into $\mathrm{SiO}_{2} @ \mathrm{C}$ NPs. The absorbing properties of materials are mainly related to magnetic loss, dielectric loss, and transmissivity on the electromagnetic wave [28]. $\mathrm{SiO}_{2} \mathrm{NPs}$ was reported to be one of the most extensive application wave-transmitting materials
$[29,30]$, and due to the interfacial polarization, coating the PPy shell on the $\mathrm{SiO}_{2}$ core could increase the complex permittivity and dielectric loss [31]. In addition, CSA has negative charges, which can increase the permittivity of $\mathrm{SiO}_{2} @$ PPy NPs. What is more, the activated carbon fibers added can assist $\mathrm{SiO}_{2} @ P P y$ NPs to absorb the microwave and enhance the heating effects [32]. The Raman results are similar in $\mathrm{SiO}_{2} @ P P y \mathrm{NPs}_{\text {and }} \mathrm{SiO}_{2} @ \mathrm{C} \mathrm{NPs}$; however, they have a significant difference in XPS results, which may indicate that changes mainly happened in forming oxygencontaining functional groups instead of the changing of the form of carbon during the microwave heating in an oxygen-containing atmosphere. Alkali could be used as a reagent to remove silica except HF to prepare hollow spheres $[33,34]$. However, in this process, not only silica successfully etched, but also a number of oxygen-containing functional groups were reduced in Hollow $\mathrm{C}$ leading to the increase in the $I_{\mathrm{D}} / I_{\mathrm{G}}$ ratio and the changes in the proportion of oxygen and carbon, which indicate that we get hollow carbon nanospheres.

\section{Conclusions}

In this paper, we reported a fast, convenient, and simple strategy to obtain hollow carbon nanospheres with a shorttime microwave heating process and an aqueous alkaline solution treatment. We used silicon as the core and PPy coating layers as the shells. We further used the microwave method to carbonize the PPy shells into carbon shells. The $\mathrm{SiO}_{2}$ NPs templates can be removed by $\mathrm{NaOH}$ to produce 
the carbon nanospheres. Compared with the traditional carbonization methods, we only need a microwave oven to obtain the carbonization products with different structure and morphology in a few minutes, which is considered to be more energy saving and efficient. We believe that this microwave-assisted synthesis method can be extended for the efficient preparation of carbon nanospheres and the preparation of different carbon materials with different nanostructure.

\section{Data Availability}

The data used to support the findings of this study are included within the article and the supporting information.

\section{Conflicts of Interest}

The authors declare that there is no conflict of interest regarding the publication of this paper.

\section{Acknowledgments}

Financial support was from the College Students' Innovative Entrepreneurial Training Plan Program (201901165, 201901161), Ministry of Education of the People's Republic of China.

\section{Supplementary Materials}

The supporting information file contains the experimental details and results, including the scanning electron microscopy (SEM) images, tables containing the experimental parameters, and transmission electron microscopy (TEM) images, to support the discussions in the manuscript. Figure S1: SEM images of EH0 (a), EH1 (b), EH2 (c), EH3 (d), EH4 (e), EH5 (f), and EH6 (g) in the experiment controlled by alcohol/H2O ratio and ET1 (h), ET2 (i), ET3 (j), ET4 (k), and ET5 (l) in the experiment controlled by alcohol/TEOS ratio. Table S1: mean particle size and standard deviation of silica spheres. Figure S2: SEM images of SiO2@PPy NPs at (a) $0 \mathrm{wt} \%$, (b) $0.1 \mathrm{wt} \%$, (c) $0.2 \mathrm{wt} \%$, (d) $0.3 \mathrm{wt} \%$, (e) $0.4 \mathrm{wt} \%$, and (f) $0.5 \mathrm{wt} \%$ concentration of CSA. Figure S3: TEM images of SiO2@PPy NPs at (a) $0.1 \mathrm{wt} \%$, (b) $0.2 \mathrm{wt} \%$, (c) $0.3 \mathrm{wt} \%$, (d) $0.4 \mathrm{wt} \%$, and (e) $0.5 \mathrm{wt} \%$ concentration of CSA. Figure S4: (a) sizes and (b) thicknesses distributions of SiO2@PPy NPs produced in different concentrations of CSA. (Supplementary Materials)

\section{References}

[1] Y. Qiao, D. Luo, M. Yu et al., “A precisely assembled carbon source to synthesize fluorescent carbon quantum dots for sensing probes and bioimaging agents," Chemistry - A European Journal, vol. 24, no. 9, pp. 2257-2263, 2018.

[2] P. Greil, "Perspectives of nano-carbon based engineering Materials," Advanced Engineering Materials, vol. 17, no. 2, pp. 124-137, 2015.

[3] S. Shahrokhian, M. Ghalkhani, R. Kohansal, and R. Mohammadi, "Biomimetic sensor for dobutamine employ- ing nano- $\mathrm{TiO}_{2} / \mathrm{Nafion} /$ carbon nanoparticles modified electrode," Electroanalysis, vol. 28, no. 5, pp. 970-978, 2016.

[4] L. Yuan, Y. Tao, J. Chen et al., "Carbon nanoparticles on carbon fabric for flexible and high-performance field emitters," Advanced Functional Materials, vol. 21, no. 11, pp. 21502154, 2011.

[5] J. Ge, Q. Jia, W. Liu et al., "Carbon dots with intrinsic theranostic properties for bioimaging, red-light-triggered photodynamic/photothermal simultaneous therapy in vitro and in vivo," Advanced Healthcare Materials, vol. 5, no. 6, pp. $665-675,2016$.

[6] B. Khezri, S. M. Beladi Mousavi, L. Krejčová, Z. Heger, Z. Sofer, and M. Pumera, "Ultrafast electrochemical trigger drug delivery mechanism for nanographene micromachines," Advanced Functional Materials, vol. 29, no. 4, article 1806696, 2019.

[7] E. Lim, C. Jo, M. S. Kim et al., "High-performance sodium-ion hybrid supercapacitor based on $\mathrm{Nb}_{2} \mathrm{O}_{5} @$ carbon core-shell nanoparticles and reduced graphene oxide nanocomposites," Advanced Functional Materials, vol. 26, no. 21, pp. 37113719, 2016.

[8] S. K. Bhunia, A. R. Maity, S. Nandi, D. Stepensky, and R. Jelinek, "Imaging cancer cells expressing the folate receptor with carbon dots produced from folic acid," Chembiochem, vol. 17, no. 7, pp. 614-619, 2016.

[9] K. Wang, H. Yao, Y. Meng, Y. Wang, X. Yan, and R. Huang, "Specific aptamer-conjugated mesoporous silica-carbon nanoparticles for HER2-targeted chemo-photothermal combined therapy," Acta Biomaterialia, vol. 16, pp. 196-205, 2015.

[10] S. Li, A. Pasc, V. Fierro, and A. Celzard, "Hollow carbon spheres, synthesis and applications - a review," Journal of Materials Chemistry A, vol. 4, no. 33, pp. 12686-12713, 2016.

[11] H. Zhang, F. Ye, H. Xu, L. Liu, and H. Guo, "Synthesis of carbon hollow particles by a simple inverse-emulsion method," Materials Letters, vol. 64, no. 13, pp. 1473-1475, 2010.

[12] Z. C. Yang, Y. Zhang, J. H. Kong, S. Y. Wong, X. Li, and J. Wang, "Hollow carbon nanoparticles of tunable size and wall thickness by hydrothermal treatment of $\alpha$-cyclodextrin templated by F127 block copolymers," Chemistry of Materials, vol. 25, no. 5, pp. 704-710, 2013.

[13] S. Kubo, R. Demir-Cakan, L. Zhao, R. J. White, and M. M. Titirici, "Porous carbohydrate-based materials via hard templating," ChemSusChem, vol. 3, no. 2, pp. 188-194, 2010.

[14] J. Liu, T. Yang, D. W. Wang, G. Q. Lu, D. Zhao, and S. Z. Qiao, "A facile soft-template synthesis of mesoporous polymeric and carbonaceous nanospheres," Nature Communications, vol. 4, no. $1,2013$.

[15] J. Kim, J. Han, D. Ha, and S. Kang, "Synthesis of nitrogen and boron co-doped carbon $(\mathrm{CNB})$ and their $\mathrm{CO}_{2}$ capture properties: from porous to hollow granule structure," Journal of Materials Chemistry A, vol. 2, no. 39, pp. 16645-16651, 2014.

[16] Y. Manawi, Ihsanullah, A. Samara, T. al-Ansari, and M. Atieh, "A review of carbon nanomaterials' synthesis via the chemical vapor deposition (CVD) method," Materials, vol. 11, no. 5, p. $822,2018$.

[17] F. Wang, X. Zhan, Z. Cheng et al., “Tungsten oxide@polypyrrole core-shell nanowire arrays as novel negative electrodes for asymmetric supercapacitors," Small, vol. 11, no. 6, pp. 749$755,2015$. 
[18] X. Song, C. Liang, H. Gong, Q. Chen, C. Wang, and Z. Liu, "Photosensitizer-conjugated albumin-polypyrrole nanoparticles for imaging-guided in vivo photodynamic/photothermal therapy," Small, vol. 11, no. 32, pp. 3932-3941, 2015.

[19] W. Stöber, A. Fink, and E. Bohn, "Controlled growth of monodisperse silica spheres in the micron size range," Journal of Colloid and Interface Science, vol. 26, no. 1, pp. 62-69, 1968.

[20] L. Zhou, G. Tan, K. Ouyang, Y. Liu, and C. Ning, "Highly water-dispersible, highly conductive, and biocompatible polypyrrole-coated silica particles stabilized and doped by chondroitin sulfate," Particle and Particle Systems Characterization, vol. 32, no. 12, pp. 1068-1077, 2015.

[21] D. An, Y. Guo, B. Zou, Y. Zhu, and Z. Wang, "A study on the consecutive preparation of silica powders and active carbon from rice husk ash," Biomass and Bioenergy, vol. 35, no. 3, pp. 1227-1234, 2011.

[22] M. Marini, F. Pilati, and B. Pourabbas, "Smooth surface polypyrrole-silica core-shell nanoparticles: preparation, characterization and properties," Macromolecular Chemistry and Physics, vol. 209, no. 13, pp. 1374-1380, 2008.

[23] T. Dai, X. Yang, and Y. Lu, "Conductive composites of polypyrrole and sulfonic-functionalized silica spheres," Materials Letters, vol. 61, no. 14-15, pp. 3142-3145, 2007.

[24] Z. Zhou, W. Zhu, J. Liao et al., "Chondroitin sulphate-guided construction of polypyrrole nanoarchitectures," Materials Science and Engineering, vol. 48, pp. 172-178, 2015.

[25] J. Rani, S.-I. Oh, and J.-H. Jang, "Raman spectra of luminescent graphene oxide (GO)-phosphor hybrid nanoscrolls," Maternité, vol. 8, no. 12, pp. 8460-8466, 2015.

[26] C. Cheng, R. Fan, Z. Wang et al., "Tunable and weakly negative permittivity in carbon/silicon nitride composites with different carbonizing temperatures," Carbon, vol. 125, pp. 103-112, 2017.

[27] B. Liang, Z. Qin, T. Li et al., "Poly(aniline-co-pyrrole) on the surface of reduced graphene oxide as high- performance electrode materials for supercapacitors," Electrochimica Acta, vol. 177, pp. 335-342, 2015.

[28] J. Shen, K. Chen, L. Li, W. Wang, and Y. Jin, "Fabrication and microwave absorbing properties of (Z-type barium ferrite/silica)@polypyrrole composites," Journal of Alloys and Compounds, vol. 615, pp. 488-495, 2014.

[29] M. F. Casula, A. Corrias, and G. Navarra, “An EXAFS study on iron-cobalt-silica nanocomposite materials prepared by the sol-gel method," Journal of Sol-Gel Science and Technology, vol. 26, no. 1/3, pp. 453-456, 2003.

[30] J. Zhu, S. Wei, N. Haldolaarachchige, D. P. Young, and Z. Guo, "Electromagnetic field shielding polyurethane nanocomposites reinforced with core-shell Fe-silica nanoparticles," The Journal of Physical Chemistry, vol. 115, no. 31, pp. 1530415310, 2011.

[31] J. Liu, Z. Wang, S. U. Rehman, and H. Bi, "Uniform core-shell PPy@carbon microsphere composites with a tunable shell thickness: the synthesis and their excellent microwave absorption performances in the X-band," RSC Advances, vol. 7, no. 84, pp. 53104-53110, 2017.

[32] T. Zou, N. Zhao, C. Shi, and J. Li, "Microwave absorbing properties of activated carbon fibre polymer composites," Bulletin of Materials Science, vol. 34, no. 1, pp. 75-79, 2011.
[33] X. Liu, Y. Liu, X. Shi, Z. Yu, and L. Feng, "Synthesis and catalytic performance of $\mathrm{SiO}_{2} @ \mathrm{Ni}$ and hollow Ni microspheres," Applied Physics A, vol. 122, no. 11, p. 987, 2016.

[34] C. Schliebe, T. Graske, T. Gemming, and H. Lang, "Metal nanoparticle-loaded porous carbon hollow spheres by twin polymerization," Journal of Materials Science, vol. 52, no. 21, pp. 12653-12662, 2017. 